\title{
O CASO MANUELLA E OS DESENHOS-PALAVRAS ${ }^{1}$
}

\author{
Maria Lúcia Batezat Duarte (Dra.)
}

\section{Resumo}

Neste artigo apresento e discuto Estudo de Caso longitudinal sobre o ensino de desenho a uma criança cega. Após apresentar brevemente o método de ensino criado e alguns resultados obtidos, são analisados desenhos recentes realizados pela menina. São desenhos motivados pela audição de palavras que nomeiam objetos concretos e palavras que nomeiam conceitos abstratos. Verifica-se assim, a função e importância do desenhar na infância mesmo para as crianças cegas. $\mathrm{Na}$ discussão final o método empregado é comparado a outros estudos sobre o desenho e a cegueira.

\section{Palavras-chave:}

Desenho de crianças cegas; ensino de desenho; desenho e significação;

O estudo longitudinal em realização com Manuella, cega de nascimento, teve início no final de 2002 e tem continuidade até o presente. (5) Em 2002, Manuella, então com 8 anos de idade, desconhecia as possibilidades de representação dos objetos do mundo pelo desenho. Quando era solicitada a desenhar ela repetia sobre o papel um processo de narrativa que lhe era muito prazeroso. Como gostava de ouvir e contar histórias reais ou inventadas, seu desenho apresentava uma seqüência de traços que ganhava dimensão, direção e ritmo de acordo com as ações do personagem. Darras (1996) denomina esse desenhar "ícones de ação".

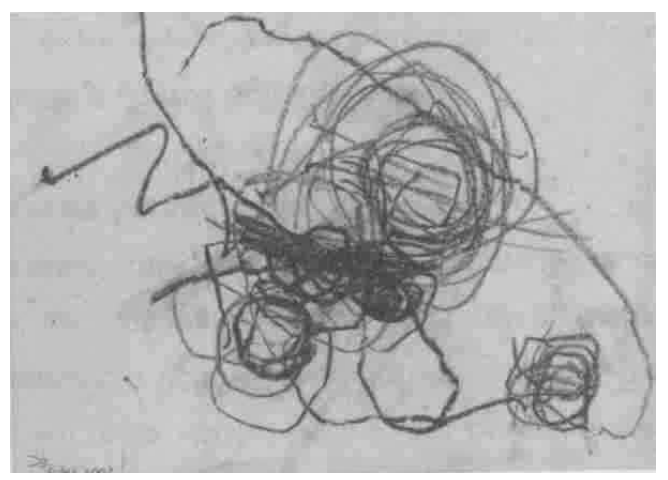

Fig. 1 - Manuella, 8 anos, dez 2002

\footnotetext{
${ }^{1}$ Projeto de Pesquisa "Desenhar sem ver: uma metodologia inclusiva para o ensino de desenho". A autora é a pesquisadora que executa o projeto (2006-2009), CEART/UDESC.
} 
Apesar de Manuella mostrar-se bastante quieta e mesmo tímida, as narrativas constituíam a abordagem mais eficaz em nossos encontros semanais. Foi a partir de histórias narradas que a configuração gráfica de objetos foi sendo ensinada e aprendida. A moradia dos personagens de uma história permitiu, por exemplo, a aprendizagem do desenho de uma CASA; a personagem central de outra história introduziu a aprendizagem do desenho de uma FIGURA HUMANA. Os traçados de "ícones de ação" eram ainda realizados por Manuella, enquanto ela experimentava tatilmente maquetes tridimensionais do objeto CASA e do objeto FIGURA HUMANA. As "bordas de superfície" das maquetes (ou o objeto real quando de pequena dimensão) eram percebidas como "linhas de contorno" e associadas às figuras geométricas. Manuella era capaz de reconhecer tatilmente o quadrado, o triângulo e o círculo, mas jamais os havia desenhado. Uma longa seqüência de exercícios foi sendo realizada a fim de viabilizar o traçado das figuras: o desenho de linhas mais longas e mais curtas em várias direções; seqüências de movimentos ondulados e sinuosos; linhas traçadas ao som de ritmos e cantigas infantis. Com estes exercícios era trabalhado o controle do gesto necessário ao desenho (e à escrita). Simultaneamente as figuras descobertas tatilmente nas maquetes tridimensionais recebiam uma versão bidimensional, mas ainda com espessura suficiente para serem percebidas tatilmente. Após, a figura conhecida por meio de maquetes tridimensionais e bidimensionais era apresentada em sua versão linear, por meio de um desenho realizado com linhas de contorno em relevo. Neste momento, Manuella recebia para percepção tátil o desenho "já desenhado" que todas as crianças standards dispõem visualmente como modelo. Ela deveria imitar o desenho e ser acompanhada, ensinada, nesta imitação como as demais crianças.

Abaixo, um exemplo da sequiência de aprendizagem: 


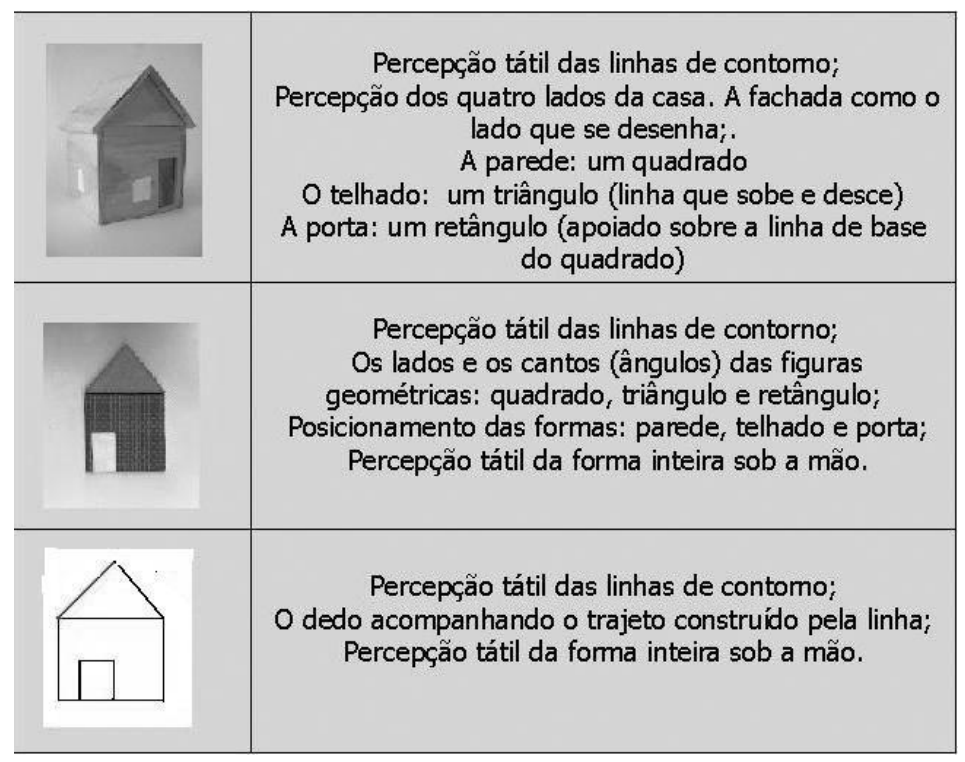

Fig. 2 - Esquema metodológico elaborado por Dannyelle Valente

Como Hatwell (2003) alerta, o trabalho com a percepção tátil e sua memorização é bem mais difícil e demorado do que o trabalho usual com a visualidade. Ao longo do tempo foi possível perceber que eu estava realizando quase dois processos de ensinoaprendizagem paralelos. No primeiro, por meio da percepção tátil, Manuella conhecia os objetos em versões simplificadas, esquemáticas, facilitadoras em relação ao tipo de percepção utilizada. Neste processo, e por meio de etapas, evoluindo da configuração tridimensional à configuração bidimensional, Manuella estava adquirindo uma concepção de desenho que requeria a planificação do objeto e a sua tradução em linhas de contorno. Mas, no segundo processo, no qual o desenho linear deveria ser realizado e repetido, percebi que, para além da memória tátil da configuração do desenho, parecia atuar com ênfase a memória motora de uma seqüência gráfica necessária. Esta percepção teve origem em algumas pistas importantes: 1) A manutenção de uma mesma sequiência de traçado da figura era essencial. Se por engano, ao iniciar o traçado, havia alguma alteração na condução do exercício, esse fato acarretava claramente um desconserto e, não raro, um impedimento à conclusão da tarefa; 2) Manuella demonstrava prazer e atenção quando, com sua mão sobre a minha mão, podia perceber a ação de desenhar, isto é, o movimento motor seqüencial que realizava o desenho. 

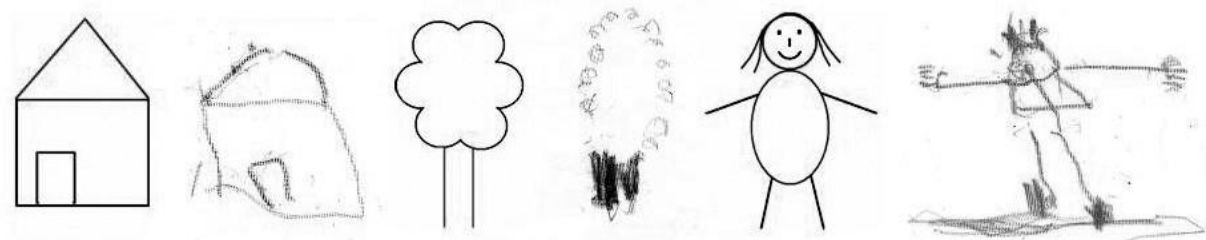

Fig. 3 - Alguns desenhos de Manuella aproximados aos esquemas gráficos geradores

Após aprender a reconhecer e desenhar esquemas gráficos básicos como casa, sol, árvore, flor, nuvem, cadeira, cão, Manuella foi apresentada ao conceito de paisagem e espacialidade por meio dos mesmos recursos de experiência física e percepção tátil de maquetes. Além disso, ela passou a autonomamente inferir outras formas e a elaborar, sem meu auxílio, representações gráficas de objetos presentes em seu cotidiano. Este fato demonstrava que, no processo de repetição e aprendizagem, Manuella adquirira uma concepção de desenho, e estava ganhando autonomia para realizar suas próprias experiências. (Duarte e Klug, 2004).
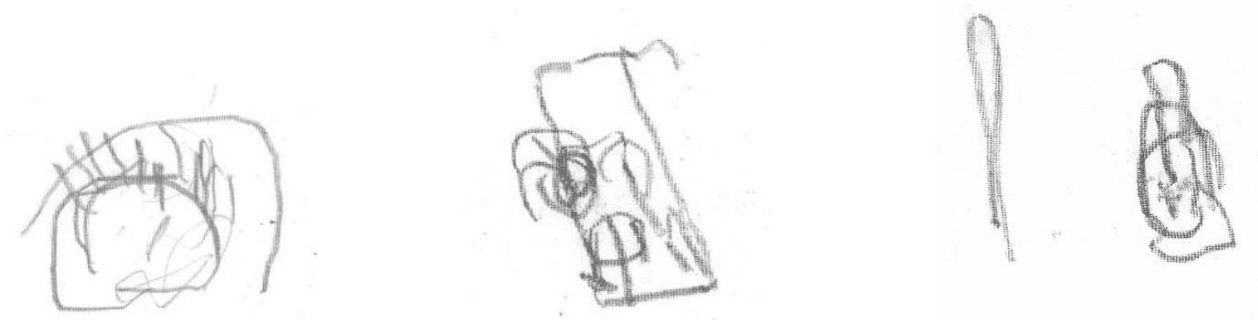

Fig. 4 - Alguns desenhos criados por Manuella no percurso de aprendizagem gráfica. (sua mão na máquina de Raio-X, uma Máquina Braille, uma Bengala)

Nos desenhos apresentados e comentados a seguir, Manuella enfrentou o desafio de desenhar a partir de uma palavra pronunciada por mim. As palavras foram selecionadas a partir de uma oposição concebida de modo simplista entre: "concreto" e "abstrato". Para esta experimentação considerei uma palavra "concreta" quando nomeava um objeto real passível de experimentação tátil; e "abstrata", quando nomeava um sentimento, uma ação, uma percepção, isto é, construções verbais que não correspondem a uma existência visual ou tátil. 


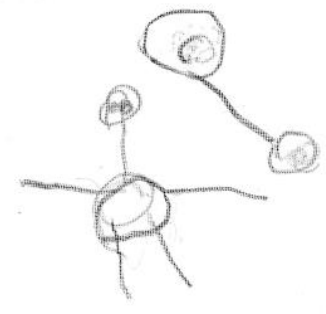

Fig. 5 - ÁGUA - (concreta)

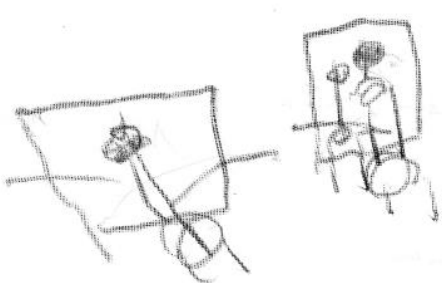

Fig. 6 - SONO - (abstrata/sensação física)

Durante a realização dos desenhos, no final do ano de 2006, foi possível observar que Manuella demonstrava grande empenho e excitação. Ela desenhava rapidamente, sem muita atenção aos detalhes, como se a rapidez fosse condição necessária ao registro integral de uma imagem mental fugaz. A análise dos desenhos e das narrativas posteriores realizadas pela menina permite ainda reconhecer que toda a palavra ouvida foi transformada em uma cena real, um registro de acontecimentos vivenciados por Manuella em tempo anterior e próximo. A aprendizagem do desenho estaria lhe propiciando a formação de um repertório de imagens mentais de cunho "visual" e gráfico? Essas imagens funcionariam como auxiliares na compreensão e significação das suas experiências de vida?

$\mathrm{Na}$ grande maioria dos desenhos Manuella representou-se como personagem central. Esse dado parece indicar que, em razão da sua incapacidade visual, a sua primeira referência de espaço é o seu próprio corpo enquanto presença física, perceptível por meio de outras modalidades sensoriais que não a visual. As construções espaciais realizadas podem estar demonstrando que Manuella tem uma concepção de espaço apesar de jamais ter experienciado visualmente as relações de proximidade e distância entre os objetos. Quando desenhou sob o estímulo da palavra SONO, adequadamente ela separou sua cama (à esquerda, possivelmente à frente) da cama dos pais (à direita e possivelmente atrás). Igualmente, representando a palavra ÁGUA ela posicionou corretamente o chuveiro sobre a sua cabeça ao desenhar-se tomando uma ducha.

Destaco a seguir alguns desenhos, entre o conjunto obtido, a fim de analisar aspectos compreendidos como relevantes: 


\section{1) O registro gráfico da audição como uma importante modalidade sensorial}

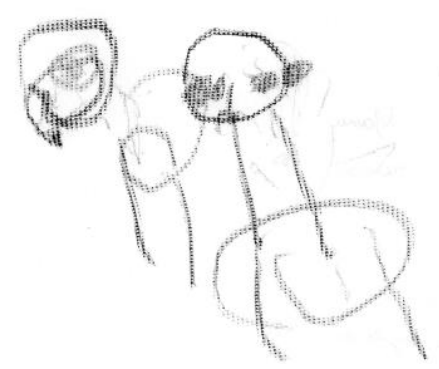

Fig. 7 - Manuella, 12 a, dez 2006, "Meg"

A palavra que originou este desenho foi MEG. Meg é nome da cadelinha de Manuella, à qual ela é muito afeiçoada. Após desenhar, Manuella disse que a cena desenhada de fato ocorrera e que ela havia passado por um susto enorme porque percebera que Meg estava no parapeito da janela, no quarto andar de seu apartamento, e poderia cair. Não há qualquer novidade formal no seu desenho, a não ser a alusão a uma cena de fato vivenciada. Entretanto, Manuella desenha a si mesmo com orelhas (os dois pontos negros laterais, na cabeça, um registrado internamente e o outro na lateral direita externa à face). Este detalhe torna evidente que a modalidade sensorial auditiva de Manuella estava altamente ativada durante a vivência da cena. Orelhas não são elementos formais utilizados nos esquemas gráficos infantis para representar figuras humanas, por isso, não haviam sido convocadas quando esse esquema foi ensinado. As partes componentes do corpo humano foram insistentemente reconhecidas tatilmente tanto no corpo de Manuella quando no meu corpo durante o processo de ensinoaprendizagem, mas a decisão de agregar orelhas ao desenho foi devida, acredito, à percepção da forte convocação da modalidade auditiva experienciada por Manuella naquele momento de susto e medo. Trata-se, provavelmente, de um desenho em que as imagens mentais de Manuella (os sinais provenientes das múltiplas modalidades sensoriais) encontravam-se altamente atualizadas na memória.

\section{2) A difícil compreensão de termos verbais qualificativos de origem visual}




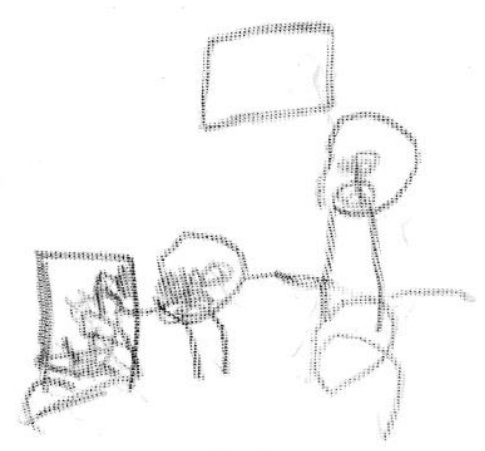

Fig. 8 - Manuella, 12a, dez 2006, "Bonito"

Neste desenho Manuella apresenta uma cena após ouvir a palavra BONITO como proposta para o ato de desenhar. A ilustração gráfica remete a uma cena na qual a palavra foi pronunciada por outra pessoa (sua mãe) significando "algo" de competência visual que, portanto, ela desconhece. Manuella soube relacionar "bonito" com uma fotografia recebida por sua mãe (à direita, no desenho). Ela ouviu a sua mãe dizer que a fotografia era "bonita", mas não foi capaz de representar pelo desenho um significado pessoal para essa palavra. BONITO era uma palavra sem sentido, sem uma concepção própria para Manuella.

Essa percepção fez com que eu trabalhasse com ela o sentido da palavra "bonito" em nossa língua portuguesa, em nossa cultura. Imitei vários tipos de vozes, repetindo sempre a mesma frase verbal, e solicitei que ela me dissesse qual, entre as vozes, lhe parecia mais sonora, mais agradável e "bonita". Falei dos cânones de beleza visual, demonstrei tatilmente em seu próprio rosto as relações (canônicas) de harmonia entre as partes que nos faziam identificar "beleza". (Depois desta nossa conversa, Manuella esteve um longo período de tempo tecendo, verbalmente, elogios a sua própria "beleza"!)

\section{3) Uma palavra "abstrata" de significado pleno e valioso}

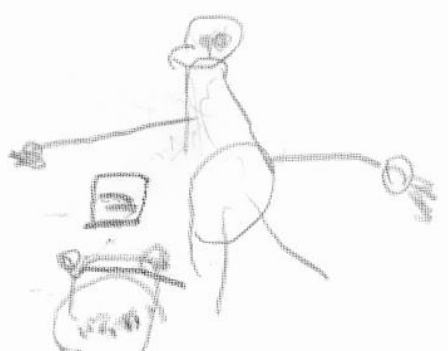

Fig. 9 - Manuella, 12 a, dez 2006, "Esperança” 
O desafio que ofereci à Manuella foi representar, desenhando, a palavra "esperança". Ela desenhou a si mesmo no centro da folha de papel, sobre a sua mão direita (à esquerda no desenho), configurou suas apostilas, impressas em Braille, e a máquina de digitar, também em Braille. Disse-me, logo após desenhar, que sua "esperança" era poder ver, e então, desfazer-se de todo material necessário às pessoas cegas.

Manuella evidenciou uma compreensão exata da palavra "esperança" e ali, na projeção de um tempo futuro, imprevisível e abstrato, depositou o seu maior desejo, revelado pelo desenho.

Neste desenho, como em tantos outros, Manuella figura-se ao centro da cena gráfica. Eu atribuo esta presença do EU em cena à escuridão que circunda as pessoas cegas. Para elas, a única presença física percebida, constantemente é o seu próprio corpo tateável, afetante e afetado, móvel, elástico, sensível, vivo. O resto é escuridão preenchida apenas por sons, ou formas fugazmente tateáveis.

\section{4) Um proto-espaço}

A palavra CAMINHÃO provocou um desenho de uma cena memorizada: Manuella aguarda na porta de casa (à direita, no desenho apresentado abaixo) enquanto sua tia buscava um material recém adquirido em um caminhão. Surpreendentemente Manuella desenhou o caminhão do modo como o desenham as crianças videntes em fases gráficas iniciais. Estudiosos do desenho infantil denominam esse modo de representação do objeto pelo desenho "rebatimento" (das rodas) ou "ponto de vista aéreo" (a carroceria do caminhão vista de cima). Estas duas "definições" aplicam-se a soluções engendradas por crianças standars, uma vez que remetem à visualidade. Tratase aqui, simplesmente, de uma solução conceitual. Manuella sabe, conceitualmente, que um caminhão possui quadro rodas, como um automóvel, para poder rodar nas ruas. Ela sabe, também, que um caminhão é maior, mais comprido, do que um carro e carrega mais objetos.

Interessa-me evidenciar especialmente, nesse desenho, o fato de Manuella ter desenhado primeiro a si mesmo, e depois ter envolvido o esquema gráfico de si nesta figura retangular inconclusa que representada a porta. Trata-se, como no desenho dos personagens na cama em "Sono", de uma compreensão rudimentar de espaço (estar dentro, estar “entre"). 
Entretanto, a dificuldade na compreensão e representação do espaço torna-se clara nos desenhos da CIDADE e do SÍTIO.

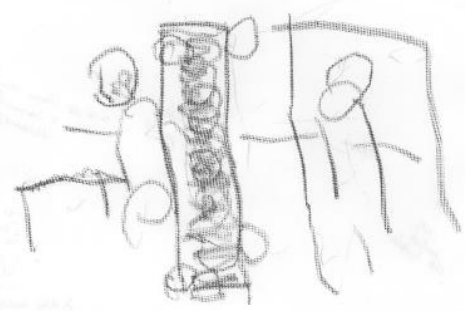

Fig. 10 - Manuella, "Caminhão"

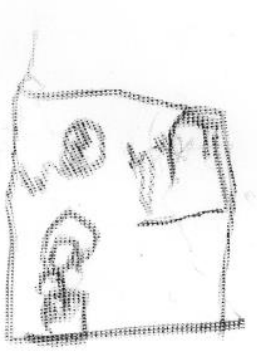

Fig. 11 - Manuella, "Cidade"

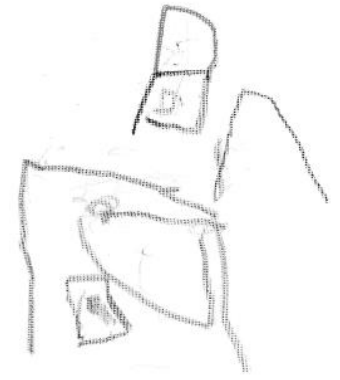

Fig. 12 - Manuella, "Sítio"

Foram evidentes o desinteresse e o desconforto de Manuella ao tentar desenhar "Cidade". Ela realizou o desenho em segundos: fechou um espaço com linhas configurando um quadrado e indicou rapidamente casas (à direita, no alto), praça (à esquerda no alto) e escola. $\mathrm{O}$ desenho parece traduzir uma compreensão limitada pelo verbal, que denuncia a ausência da experiência visual. A cidade é na concepção de Manuella um espaço limitado (pela linha que configura um quadrado) onde existem casas, praças e escolas.

Para desenhar SÍTIO (7), Manuella desenha uma casa e uma montanha (na parte superior do desenho) conforme os esquemas gráficos aprendido em nossos encontros semanais. Indica a porteira do sítio com um traçado idêntico aquele aprendido para representar "porta". Com uma forma triangular diz estar demonstrando as cercas do sítio. O pequeno retângulo, dentro da porteira e sob o triângulo-cerca, representa um ônibus (Manuella havia realizado um passeio a um sítio, com seus colegas de escola).

Com a idade de Manuella, as crianças videntes já adotam para desenhar o "ponto de vista único", isto é, constroem o espaço de representação gráfica a partir de um observador que vê em frente a si mesmo, em ângulo máximo de $180^{\circ}$, a cena a ser desenhada. Esta experiência de "pontos de vista", da "direção do olhar" é construtora da noção de espacialidade. A ausência de percepção espacial dificulta profundamente a locomoção autônoma das pessoas cegas de nascimento. Essa dificuldade é muitas vezes superada por aqueles que preservam, especialmente na perda de visão progressiva, um percentual mínimo (5\%) de percepção visual. 


\section{5) Desenho e cognição}

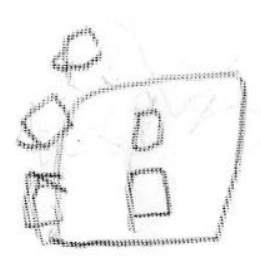

Fig. 13 - Manuella, ago 2007 "Prédio 1"

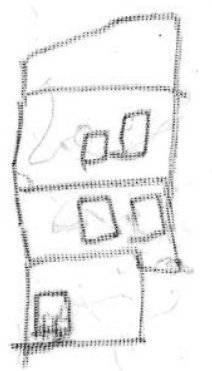

Fig. 14 - Manuella, ago 2007 "Prédio 2", após aprendizagem

Em agosto de 2007, quando retomamos nossos encontros Manuella havia mudado de residência. Seus pais e ela estavam morando em um apartamento maior. Manuella estava feliz com a sua casa nova. Ela perguntou-me de improviso: Como é [o desenho de] um prédio de apartamentos? Respondi: Primeiro eu quero que você me mostre como você imagina que seja... Então, Manuella realizou o primeiro desenho, à esquerda. Percebi que ela registrara graficamente a idéia de uma pluralidade de casas, apesar da sua dificuldade em construir mentalmente uma imagem vertical dessa pluralidade. Expliquei, então, que os prédios de apartamento possuem escadas ou elevadores porque as "casas" ficam umas sobre as outras. Com um jogo de cubos, mostrei tatilmente a posição sobreposta, verticalmente, de várias casas (cubos). Então, Manuella fez o segundo desenho, vertical, sobrepondo "casas" como havíamos sobreposto os cubos. Depois, ela foi completando com porta e janelas, de acordo com a seqüência de nossa conversa sobre a fachada dos prédios de apartamentos. No final perguntei-lhe por que ela havia pedido para desenhar um prédio de apartamentos. A resposta foi rápida: - Porque desenhando eu posso conhecer!

\section{Considerações finais:}

John M. Kennedy, professor de psicologia da Universidade de Toronto, estuda o desenho de pessoas cegas há longos anos. Ele realiza investigações transversais com participantes adultos, cegos precoces e tardios. Os testes utilizados envolvem leitura tátil de imagens e a produção de desenhos. Em sua trajetória, Kennedy (1983, 1993) também investigou se pessoas de culturas diferentes, sem contato com reproduções imagens (fotografias, etc.) e desenhos, eram capazes de identificar objetos representados 
graficamente por meio de desenhos lineares (linhas de contorno). A resposta a estes teses foi positiva. Isto é, Kennedy constatou que pessoas adultas videntes, mesmo que jamais houvessem tido contato com representações bidimensionais de objetos conhecidos, eram capazes de identificá-los em representações gráficas lineares simples. Eram, entretanto, incapazes de reconhecer efeitos gráficos como sombreados ou texturas gráficas visuais. São também lineares (grafados com linhas de contorno) e sem efeitos de sombreados ou texturas os desenhos obtidos com pessoas cegas adultas (Kennedy, 1983).

São as seguintes as teses de Kennedy: a) cegos e videntes possuem em comum a capacidade de perceber pelo tato, ou pela visão, as bordas de superfície dos objetos (linhas de contorno); b) videntes e não-videntes possuem a mesma capacidade de registrar, pelo desenho linear, as impressões obtidas pela percepção tátil ou visual das linhas de contorno dos objetos; c) as percepções visuais e/ou tátil das bordas de superfície dos objetos são semelhantes (universais) para todos os seres humanos; d) como as crianças videntes, as pessoas cegas são capazes de desenhar "naturalmente", autodidatamente, sem que qualquer aprendizagem se faça necessária. Ainda que, para os cegos, seja imprescindível um recurso de desenho que garanta o relevo tátil da linha grafada (Kennedy, 1993).

Frente às teorias sobre a aprendizagem baseada na imitação (Winnikamen, 1990), às descobertas dos neurônios espelhos (Jeanneroud, 2004), e às minhas investigações sobre o desenho infantil e o desenho de pessoas cegas, questiono o caráter "autodidata" conferido por Kennedy ao desenho de pessoas cegas. Considero que a capacidade de ler imagens bidimensionais é diferente da capacidade de fabricar essas imagens. A produção de desenhos exige procedimentos mais complexos, que envolvem especialmente o sistema sensorial motor.

Acredito que, para conhecer a natureza do desenhar de crianças e adultos, videntes ou não-videntes, é necessário conhecer as origens, a história pessoal de esse desenhar. Grande parte da pesquisa de Kennedy foi realizada em um período no qual o princípio da "criatividade" era, especialmente nos países do "Novo Mundo" (entre os anos 50 e 80), considerado condição para uma atribuição de valor às produções gráficas ou pictóricas dos sujeitos. Neste período, por exemplo, raramente as fontes de imagem dos desenhos infantis foram investigadas. Pioneiros nesse estudo Brent e Marjorie Wilson identificaram em estudo quantitativo e qualitativo (Wilson e Wilson, 1974) que 
a cópia de desenhos de familiares, colegas e revistas constituíam as principais fontes desses desenhos.

Como os cegos aprendem? Ainda muito distante dos números de investigação obtidos por Kennedy, posso apenas construir algumas hipóteses com os dados já obtidos:

1. Para desenhar é necessário obter um conceito de desenho, isto é, compreender a possibilidade de transformar as bordas de superfície dos objetos do mundo físico, percebidas visualmente ou tatilmente, em linhas de contorno gráfico;

2. As crianças videntes começam a realizar experiências gráficas espontaneamente, naturalmente, por imitação à escrita dos adultos. Após um período de rabiscos (garatujas) aleatórios, elas passam a controlar o movimento motor integrado de mão, dedos e braço, e a dirigir o seu traçado descobrindo, por analogia morfológica, às primeiras representações gráficas. Quando a criança descobre a sua possibilidade de representação dos objetos do mundo pelo desenho e apresenta essa conquista aos pais ou professores, ela passa a ser auxiliada nessa tarefa. Pais, professores, irmãos mais velhos, coleguinhas já iniciados, passam a indicar soluções e a construir exemplos gráficos que facilitem o desenhar do pequeno iniciante;

3. Crianças cegas, como Manuella, embora desenhem rabiscos, não começam "naturalmente" a representar pelo desenho os objetos do mundo. Elas não podem construir sozinhas uma concepção de desenho porque não podem ver. Elas não podem imitar o ato de escrever ou desenhar dos pais e de crianças mais velhas. Elas poderão iniciar "naturalmente" e "espontaneamente" seus desenhos se alguma concepção de desenho for adquirida em situações como: a) aulas de geometria na qual o desenho de sólidos geométricos seja realizado com linhas com relevo em superfície bidimensional; b) brincadeiras com familiares ou colegas em que o ato de desenhar seja compartilhado com a criança (ou o adulto) cega por meio de desenhos realizados em linha de relevo tátil ou, no mínimo, essa criança entre em contato com representações bidimensionais de objetos grafadas em linhas com relevo como, por exemplo, ilustrações de personagens e objetos em livros de historinhas infantis.

Nas duas situações hipotéticas atribuo, como um a priori ao desenhar de crianças cegas, uma situação de aprendizagem do código linear do desenho o qual, na ausência da visualidade, não pode ser apreendido como experiência visual, isto é, como 
um "golpe de vista". Mas, deverá ser aprendido como uma seqüência tátil perceptiva na qual a possibilidade de tatear o objeto em sua tridimensionalidade deve encontrar paralelismo com a necessária simplificação e esquematismo do desenho bidimensional em linha com relevo tátil.

Lola Bardisa (1992) optou por ensinar às crianças cegas o desenho da silhueta dos objetos. Aprendizagem semelhante é perceptível nos desenhos de Tracy (28 anos, cega desde os 2 anos), participante da investigação de Kennedy, especialmente para o desenho dos animais. Tracy desenhava um cavalo, por exemplo, no qual pernas, pescoço, cabeça, corpo e rabo eram delineados por meio de uma única linha contínua que revelava apenas o contorno geral da figura (silhueta). Esse fato parece indicar um processo de aprendizagem no qual a figura bidimensional do cavalo, por exemplo, recebia um tratamento em relevo a fim de permitir que Tracy percebesse o seu contorno em linha contínua. Bardisa segue o princípio apontado por Kennedy sobre a equivalência entre a percepção visual e a percepção tátil em relação às bordas de superfície dos objetos e, por isso, ensinou o desenho de silhueta.

Entretanto, quando desenham as crianças standards não traçam uma linha contínua. Elas compõem as figuras gráficas a partir das propriedades formais elementares dos objetos. Desenham: cabeça, tronco, pernas, orelhas, rabo, para desenhar um animal quadrúpede. (8) Esse processo implica o reconhecimento e a classificação do objeto desenhado em uma categoria cognitiva (nesse caso, a categoria dos animais quadrúpedes). Implica a compreensão de um conceito de "animal quadrúpede”.

No exemplo a seguir, demonstro as diferenças de concepção entre o desenho de silhueta e o desenho de esquemas gráficos infantis:

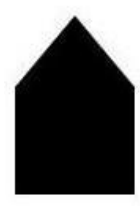

A

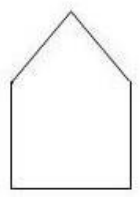

B

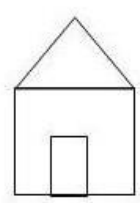

C

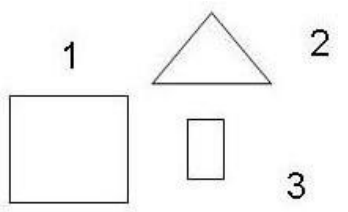

D

Fig. 20 - A: silhueta de uma casa; B: silhueta linear (desenho) de uma casa; C: desenho do esquema gráfico CASA como as crianças o desenham; D: a possibilidade de separação e reunião das partes para a compreensão dos componentes formais essenciais ao conceito de casa (paredes, telhado e porta) 
O procedimento utilizado pelas crianças standards marcado pela percepção da totalidade do objeto, seguido pela decupagem desse objeto em seus componentes formais elementares para a (re)construção da figura gráfica, foi mantido na experiência com Manuella. Nesse trabalho mental entre a percepção da totalidade e a reconstrução da totalidade pela partes essenciais que compõem o objeto, e o seu desenho, a fim de que ele seja identificável (reconhecível) tatilmente e também visualmente garante dois processos fundamentais: que o desenho realizado pela criança cega seja legível por qualquer criança, vidente ou não vidente, seja portanto um desenho "comunicacional" (Darras, 1996, 1998; Duarte, 1995); e que um processo de cognição, isto é, de reconhecimento e classificação (conceituação) dos objetos do mundo, pela sua configuração formal, seja plenamente realizado.

\section{Referências Bibliográficas:}

BARDISA, Lola. Como enseñar a los niños ciegos a dibujar. Madrid: ONCE,1992.

DAMÁSIO, Antonio. O mistério da consciência. Tradução Laura Teixeira Motta. São Paulo: Companhia das Letras, 2000.

DARRAS, Bernard. Au commencement était l'image. Du dessin de l'enfant à la communication de l'adulte. Paris: ESF Éditeur, 1996.

DUARTE, Maria Lúcia Batezat. $O$ desenho do pré-adolescente: características e tipificação. Dos aspectos gráficos à significação nos desenhos de narrativa. Tese de Doutoramento. São Paulo: ECA/USP. 1995.

DUARTE, Maria Lúcia Batezat. Imagens mentais e esquemas gráficos: ensinando desenho a uma criança cega. In: MEDEIROS, Maria Beatriz (org) Arte em pesquisa: especificidades. Ensino e aprendizagem da arte e linguagens visuais. Brasília, DF: UnB, V2, p.134-140, 2004.

DUARTE, Maria Lúcia Batezat e KLUG, Alessandra. Diário de Manu: Revelando a aprendizagem do desenho por uma criança cega. Dapesquisa. Revista de Investigação em Artes. Florianópolis, v. 01, p. 1-13, 2004.

GUÉRIN, Fanny. SKA, Bernardette. BELLEVILLE, Sylvie. Cognitive processing of drawing abilities. Brain and Cognition, n. 40, p. 464-478, 1999.

HATWELL, Yvette. Psychologie cognitive de la cécité précoce. Paris : Dunond, 2003.

HOUDÉ, Olivier. La psychologie de l'enfant. Paris: PUF, 2004

JACOB, Pierre e JEANNEROUD, Marc. The motor theory of social cognition. A critique. Interdisciplines. http://www.interdisciplines.org/mirror/papers/2, em 30nov2005.

KENNEDY, John M. "What can we learn about pictures from the blind? Blind people unfamiliar with pictures can draw in a universally recognizable outline style. American Cientist, US, V.71: p.19-26, jan-feb, 1983.

KENNEDY, John M. Drawing \& the blind. Pictures to touch. Yale University, New York: Vail-Ballou Press.

LUQUET, Georges-Henri. Les dessins d'un enfant. Paris: Félix Alcan, 1913.

LUQUET, Georges-Henri. $O$ desenho infantil. Tradução Maria Teresa Gonçalves de Azevedo. Porto: Ed. Minho, 1969. Primeira Edição 1927. 
RICHARD, Jean-François. Les activités mentales. De l'interprétation de l'information à l'action. Paris: Armand Colin, 2004.

ROCHA, Armando F. O cérebro. Um breve relato de sua função. Jundiaí: EINA, 1999.

SACKS, Oliver. Um antropólogo em marte. Sete histórias paradoxais. São Paulo:

Companhia das Letras, $8^{\mathrm{a}}$ re, 2002.

VYGOTSKY, Lev S. La imaginacion y el arte en la infancia.Madri: Akal Editor, 1982.

WALLON, Henri. LURÇAT, Liliane. El dibujo del personaje por el niño. xerox s/d. 